\title{
Research on the Influence of VR Technology on Product Design
}

\author{
Chen Chen ${ }^{1,2}$ \\ ${ }^{1}$ Guangzhou University \\ Guangzhou, China \\ ${ }^{2}$ Department of Industrial Design \\ Pukyong National University \\ Busan, Korea
}

\author{
Cho Joung Hyung* \\ Department of Industrial Design \\ Pukyong National University \\ Busan, Korea
}

\begin{abstract}
As virtual reality (VR) technology progresses, the application of it is constantly expanding and it has been penetrating in many fields. The research object of this article is to explore the development trend of future product design and the feasibility of integrating VR technology according to the movements of the current product market and the needs of customers. The purpose of this paper is to apply VR technology to the process of product design, to bring advantages and value to product development and innovation, and to bring convenience and scientificity to the creation of designers. By adopting comparative analysis and enumerating instance, this paper analyzes and studies the characteristics, practicability, display mode of VR technology in the present stage, and elaborates its influence on the product design realm. In the digital era, VR technology enables customers to form a renewed cognition for the appearance, functionality, and operation of modern products. The product design should also find applications and expansion in the development of digitalization and virtualization. The application of VR technology can provide more forward-looking ideas for product design.
\end{abstract}

Keywords-VR technology; product design; virtual reality; Digital

\section{INTRODUCTION}

VR, generally refers to virtual reality, is a computer simulation system that can create and taste the dummy world. It is a cutting-edge discipline with challenging cross-technology, and a sought-after research field. VR technology can simulate three-dimensional images with the condition and content all generated by computers. It was a concept proposed by the founder of the VPL Company, Jaron Lanier, in the early 1980s. It is a simulation system that can realize physical behavior and can break through space, time, and other objective restrictions to immerse users in a virtual environment where they can experience things that cannot be accessed in the real world. The most prominent feature of VR technology is panoramic operation. Many industries at this stage are gradually participating in the virtual reality industry.

VR technology can not only simulate the real environment, but also create an objective world beyond reality in which the participant can control the virtual environment through interactive behavior, feeling actually being there. The virtual reality system can be widely applied to various fields, creating everything that is existed or unborn. In the information era, knowledge in various fields are mutually integrated and promoted, which brings a lot of room to promote the development and application of VR technology. The experiencer in the virtual reality system is not passively accepted, but is the controller or the planner, and can highlight the relationship between the virtual world and the real world. The virtual world is not created out of nothing but on the basis of real world simulation and reengineering [1].

Today's VR technology can also be used as an analysis tool for man-machine system design engineering. It can realize a variety of creative methods and provide a lot of advanced methods to solve problems. Today it has achieved success in many fields and become one of irreplaceable R\&D tools in military simulated experiments, film, video and television entertainment, game development, and medical research.

\section{Application of VR Technology in Product DESIGN}

Nowadays, the competition of science and technology is always the focal point of the competition among various fields. As for product design, we must first meet the needs of society, and we need to constantly upgrade the design concepts and methods according to the development of the times. Then, we need to make innovations and develop new products, promote the progress of design methods and draw on the world's advanced science and technology. And it needs to be used rationally and purposefully to address gaps in technology. "Innovation" is an important standard for product design. It is the designer's responsibility to develop new products, innovate design concepts, and expand markets. In the information age, product design methods and ideas are also changing. We can satisfy the material demands of consumers by achieving the transformation from high-tech to innovative products with modern scientific and technological achievements

\section{A. Analysis of the status quo of product design}

For traditional product designers, drawing with pencils, erasers, and triangle rulers is not efficient, and the design process is cumbersome. With the development and use of computer software, though software can be used to assist in drawing, it is boring and tedious. As the market changes, the demand for products from society is also growing. Thus, to ride the wave of the market, product manufacturers have to embrace 
the new demands on the production cycle to become highly efficient, diversified, and time saving. Traditional product design methods can no longer adapt to the ever-changing market[2]. With the progress of digitization and virtual technology today, these difficulties can be overcome. The application of virtual reality technology in design will change the evaluation criteria for design quality. The traditional renderings of charts will become meaningless in front of virtual models that possess both high degree of realism and interaction. As for the product, users are now focusing more on its innovation, aesthetics, and functionality.

\section{B. Development of VR technology in design field}

Currently, VR technology has been involved in graphic design, interior design, apparel design, and product design. For example, “Tilt Brush”, painting software developed by Google, allows designers to create with imagination in space by putting on the VR glasses, so that they can complete some of the design work intuitively. In the automotive design industry, automotive designers in the Immersion laboratory at Ford Motor Co., use virtual reality headset to enter the virtual environment where they can observe more details, and the size of the parts, the brightness of the lights, and the shape and position of other design elements can all be calibrated and estimated in the virtual reality space.
Modern design needs to satisfy varied consumer demands. VR technology can design and process on the basis of traditional design, shape product through computer simulation technology and achieve three-dimensional display of the product features, appearance and texture by the application of computer technology and information technology. And the user's intuitive experience provided by it can enhance the competitiveness of modern design products in the market and promote the development.

\section{Application of VR technology in modern product design}

VR technology has gained fruits in many fields. The application of virtual reality technology to product development can make the design method and process more simplistic and scientific. For example, Nike has been trying to use VR technology to design more excellent sports shoes in recent years, and it has also begun to introduce related technologies in the design process. The combination of 3D modeling and virtual reality in the design process improves design efficiency and sparks designers' inspiration. Moreover, designers are available with comprehensive data information throughout the process.
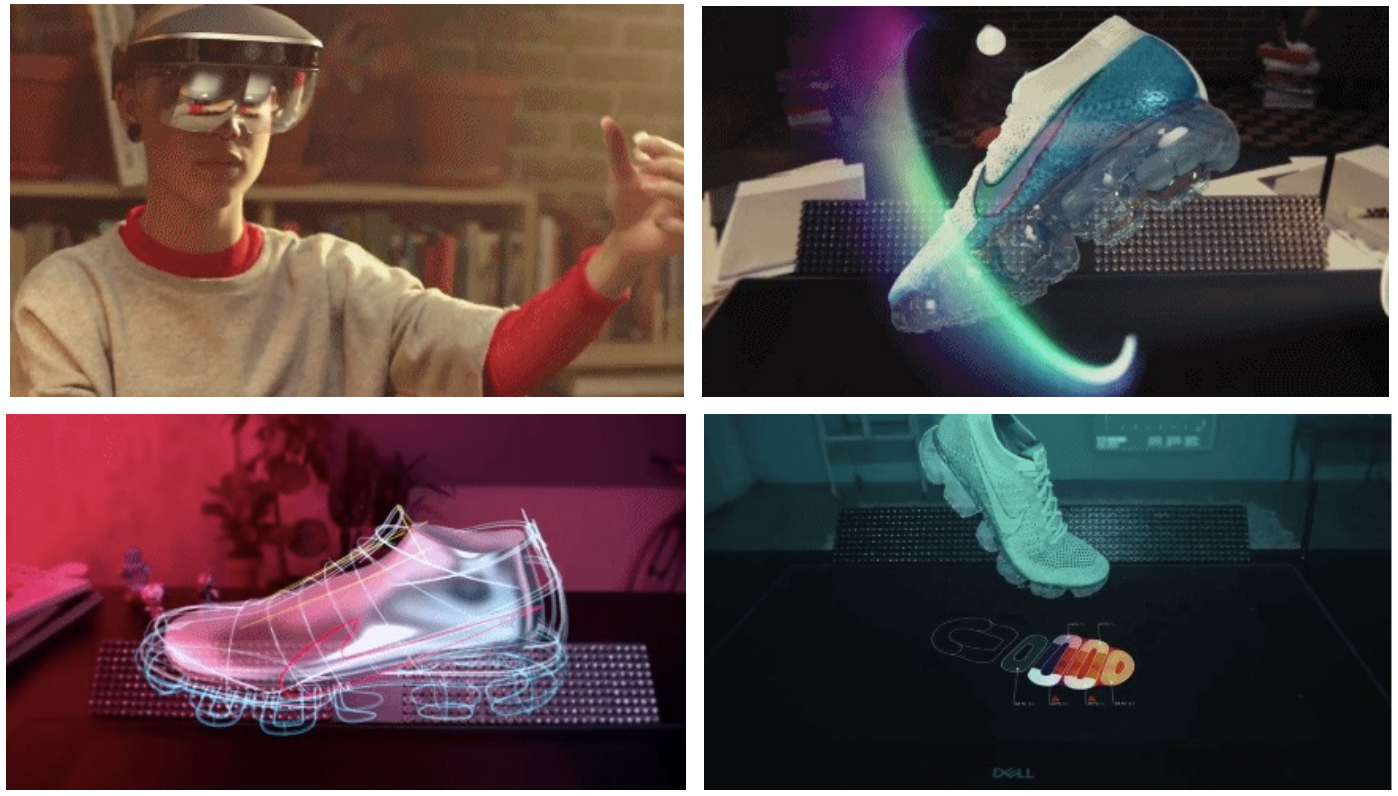

Fig. 1. Nike uses VR technology to design sports shoes

Using VR technology can shorten the product design and development cycle, and can offer a comprehensive interpretation of the product's appearance, color, function, use, etc. The emergence of virtual reality technology will exert influence on the modern product design method. Advanced design techniques and production methods matter most if all design products want to stand out in the market due to the fact that product design are now centering on innovation and technology. VR technology can break through the shackles of two-dimensional graphic design on the basis of traditional product design, use computer simulation technology and artificial intelligence technology to recreate the product's appearance, and display the main usage and characteristics of the product in three-dimensional space[3]. VR technology applied to the design of modern products allows designers to make a comprehensive evaluation of the product design program, and illustrate the design concept and use of methods to users through three-dimensional interactive expression. 
In the product design, researches should be conducted on design plan and user mentality in the early stage, which can proceed by phases. First, it comes to the innovation of design concept. When integrated with VR technology, it can conduct analysis on variability and feasibility. The next step is to complete the three-dimensional model and produce the animation of the product. Using VR technology to realize the interaction between people and products, set the product space according to the user's habits as far as possible, and create a user experience space is the most effective way to present products, and it will also be the development trend of innovative product design.

\section{INFLUENCE OF VR TECHNOLOGY ON PRODUCT DESIGN}

The characteristics of simulation and visualization of VR technology can bring development opportunities for product design. VR technology can display the appearance, material, components, and internal structure of the product through three-dimensional imaging which will show the image and the strength of the company, and also facilitates users to have a deeper understanding of the product. The application of VR technology in modern product design enables designers to more intuitively recognize the texture, shape, and function of the product through product simulation during the product design process and to make timely correction when finding weak points[4]. The use of virtual reality technology can improve the design efficiency, shorten the production time, reduce design costs, and promote competitiveness, thus increasing the profitability of goods. After trying out products in a virtual environment, consumers can give feedback directly, which can effectively reduce the loss of direct investment in market operations.

\section{A. Practicality of VR technology in product design}

Combining theories of statistics, graphics, human-computer interaction techniques, VR technology can provide people with visual, auditory and olfactory experience. People adopt VR technology to achieve data visualization, and the most important is the display of the shape and function of the product. To some extent, the designer can fully express the designing concept and style of the product, so that designer's design capability and creativity can be presented to customers in commercial display and promotion activities[5]. Designers can create a contagious environment for customers to interact with products by using spatial planning, layout, light control, and color configuration, which are based on the features of virtual reality.

\section{B. VR technology provides a new creative space for product design}

The interactive, immersive and imaginative nature of VR technology provides a superior platform for product display. And in the design process, the designer can enter into another state of consciousness where his self-perceived ability can reach the peak. In this state, attention will become very concentrated, and all design inspiration will be gathered in the virtual environment. This will not only bring about a more intuitive experience, but also locate design deficiencies in it in the meantime. Designers can try out all innovative design ideas sparked during the product design process in the virtual environment, during which VR technology can help designers brain storm design ideas, and assist in organizing and complete the complex designing, making the design process more interesting. In the process of experiencing, all kinds of information of the products will be presented in front of the customers. They will form a multi-dimensional understanding of product features and uses through the close interaction between products in reality an in virtual environment. New experience modes and cognitive methods of products created by VR technology can change people's understanding of products, and allow them experience innovative design in both digital and information age. The application of VR technology can also enhance the competitiveness of the product in the market in that it adds a certain sense of technology and future to the product.

In the design process, the product has the requirements of investigation, design plan and effect evaluation. VR technology can be applied to the most critical evaluation stage. Using products and environments presented by 3D virtual technology, instead of traditional product models for testing will optimize and improve design scheme. VR technology as a creation and display platform, flexible interaction and immersive experience can provide a brand-new creative space for product design. Moreover, the sales channel of products can be expanded. The product can be displayed to customers through digital marketing methods such as video, animation, and network, which can spare the time and space for publicity. This not only saves manpower but also improves the efficiency of information dissemination. VR technology can present products to customers in the shortest time both vividly and concretely, allowing them to quickly grasp the features and usage of products and more comprehensive information. What's more, in the process of experience, customers can respond to a series of operations in real time, so that the designer can correct the designed products in time and create excellent design products for the current market.

\section{VR technology can provide new display platform for products}

With VR technology, customers can have 360-degree views of the product's appearance, internal, and methods of use, and the information like product maintenance and usage presented can greatly increase customers' inclination to buy and use. At the same time, the user can also feel the designer's design concept and experience the pleasure of using the product, which can not only meet the subjective demands of the customer, but also create a subjective environment according to the customer's needs, satisfying the customer both visually and spiritually. 


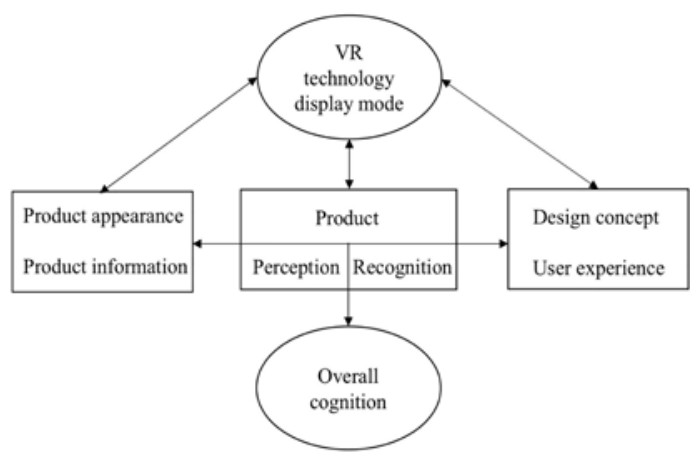

Fig. 2. Example of VR technology's overall product awareness

The traditional display is classified into active display and passive display. Using VR technology, customers can observe more authentic products in a computer-generated virtual environment. Along with this, users can make effective choices and judgments by seeing, touching and hearing in the virtual world. In the virtual display, customers can interact with objects through interactive devices such as helmet-mounted displays and data gloves and immerse themselves in the virtual environment. Interactive actions can be set in a threedimensional virtual scene, allowing customers to observe and touch products, and receive visual and auditory feelings generated by information in a variety of ways. Meanwhile, in a virtual environment, customers are the main players, and can interact with products. Customers can purposefully interact with the product, so that increase customer satisfaction with the product, and satisfy customer's subjective needs.

\section{CONCLUSION}

The invention of the steam engine allowed humans to enter the industrial society. The emergence of the Internet brought humans into the information age. The digital time and virtual reality technology will bring about revolutionary changes in human society. The application of VR technology in product design leaves more room to grow the design, and changes the display pattern of traditional product models. Designers can incorporate the latest design concepts into product design, which also promotes the development of modern design. The characteristics of simulation and three-dimension will bring great changes to product design, and inspiration and creative space to designers. Currently, VR technology has gradually been accepted and even been sought after. The application of it in product design is the only way for future product design and development, and because virtual technology can provide a good creative platform for product design, complete operation and display in the design process, designers can feel its convenience and intuitiveness. Besides, the display features of VR technology can optimize the interactive platform for customers, leading to more intuitive understanding of product information and features. In a nutshell, the development and application of VR technology in product design will give rise to the more perfect display of products.

\section{REFERENCES}

[1] Wu Xiaoming, Bo Rong. The Era of Virtual Reality-A Gateway to Future Industry.[M].Beijing: China Machine Press, pp. 35-48, 2016.8

[2] Jennifer Hudson. Process: 50 Product Designs from Concept to Manufacture.[M].Beijing: China Youth Publishing Group, pp. 12-34, 2009.8

[3] Zhang Liangjie. Research on The Current Position of VR Technology and Its Application [J].Sensor World,2017.5

[4] Talent Limited Liability Company. VR is Coming! The Next Technology Platform to Reshape Social Contact and Subvert The Industry. CITIC Press, pp. 23-42, 2016.10

[5] Kingyo Xie. Design Future: Guide on VR virtual reality design. Publishing House of Electronics House, pp. 54-73, 2017.7 